\title{
Difficult airway management in Apert syndrome for maxillofacial reconstruction: a case report
}

\author{
Purwoko Purwoko ${ }^{1}$, Andre Azhar ${ }^{2} \varangle$, Septian Adi Permana ${ }^{3} \bowtie$
}

\begin{abstract}
Author affiliations:
Faculty of Medicine, Universitas Sebelas Maret, Ir. Sutami 36A Street, Jebres, Surakarta City, Province of Central Java, Indonesia.
\end{abstract}

Correspondence: Purwoko Purwoko; E-mail: purwokoanest@gmail.com; Phone: +62011285616; Mobile: 0062811285616

\section{Abstract}

Apert syndrome (AS) is an autosomal dominant disease associated with several craniofacial and limb deformities. Craniofacial deformities in AS patients requiring surgery are usually associated with difficult airway management. We report a case of a 21-year-old male patient, ASA III, with AS, who had a mandibular fracture and reconstruction was planned. The patient had all the features of AS. He had no comorbidities such as hypertension and diabetes mellitus. Awake intubation with fiberoptic bronchoscope was planned. In these patients with AS, intravenous access might also be difficult due to limb deformities. Some surgical procedures make intravenous access even more difficult. Rarely, if intravenous access is judged to be mandatory in an emergency, intraosseous or intramuscular access may be an alternative.

Abbreviations: AS - Apert syndrome; ED - emergency department; MSCT - Multislice Computerized Tomography

Key words: Apert syndrome; Acrocephalosyndactylia / diagnostic imaging; Acrocephalosyndactylia / pathology; Syndactyly / pathology; Maxillofacial reconstruction, Airway management

Citation: Purwoko P, Azhar A, Permana SA. Difficult airway management in Apert syndrome for maxillofacial reconstruction: a case report. Anaesth. pain intensive care 2021;26(1):119-122. DOI: 10.35975/apic.v26i1.1781

Received: October 27, 2021, Reviewed: November 11, 2021, Accepted: November 14, 2021

\section{Introduction}

Apert syndrome (AS) is also known as acrocephalosyndactyly. It was first reported by Wheaton in 1894, and by a French pediatrician Eugene Apert, in 1906. ${ }^{1}$ This syndrome is believed to be associated with mutations in Fibroblast Growth Factor 2 (FGFR2) that would cause anatomic abnormalities. ${ }^{2}$ AS has a prevalence of 1:100,000, and is the second most common form of craniosynostosis syndrome. This syndrome is a form of acrocephalosyndactyly type 1 with autosomal inheritance characterized by brachiocephalic type acrocephaly and hand and foot syndactyly. ${ }^{3}$ This syndrome is characterized by brachycephaly, craniosynostosis, midface hypoplasia, hypertelorism, choanal stenosis, multiple-digit hand and foot syndactyly. Associated abnormalities include heart defects, polycystic kidney and pyloric stenosis. ${ }^{4}$

The diagnostic criteria for AS have not been published. Molecular genetic tests identifying heterozygous pathogenic variants on FGFR2 identical to AS are possible but expensive. Early diagnosis of AS should be suspected in individuals with suggestive findings such as craniosynostosis, characteristic dysmorphic facial manifestations, and syndactyly of the hands and feet with bone involvement. ${ }^{5}$

Anatomical abnormalities in AS pose a serious challenge to the anesthesiologists, especially during general anesthesia. Difficulties associated with airway management are a major concern, and clinicians should be aware of other complications and difficulties such as bronchospasm, wheezing, and even difficulty in intravenous access.

\section{Case report}

A 21-year-old man came to the emergency department (ED) with complaints of pain in the jaw and left side of the face. He had headache that was not accompanied by vomiting, fever, shortness of breath, chest pain, or cough and cold. He had a traffic accident seven days ago. At the 
time of the accident, there was no loss of consciousness and/or vomiting. The patient had a history of hand revision surgery three times in the past 20 years. The anesthetic technique used was general anesthesia. A history of chronic diseases such as hypertension, diabetes mellitus, and allergies was denied. The patient on arrival in the ED was moderately ill with Glasgow Coma Scale (GCS) E4V4M6, blood pressure 130/87 $\mathrm{mmHg}$, heart rate 100 beats/min, respiratory rate 18 breaths/min, temperature $36.6^{\circ} \mathrm{C}$, and oxygen saturation $\left(\mathrm{SpO}_{2}\right) 99 \%$ on room air. The results of the physical examination revealed several abnormalities, including exophthalmos in both eyes, decreased

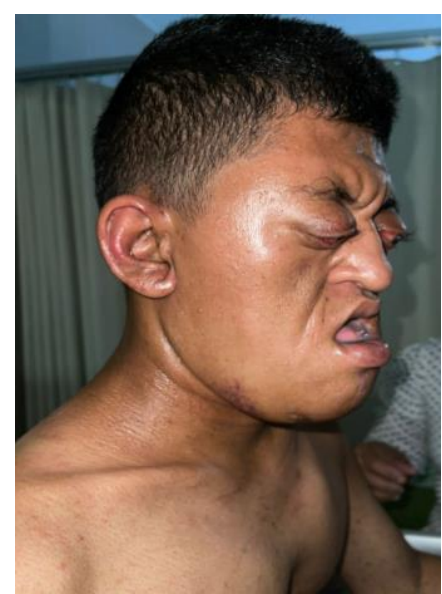

(a)

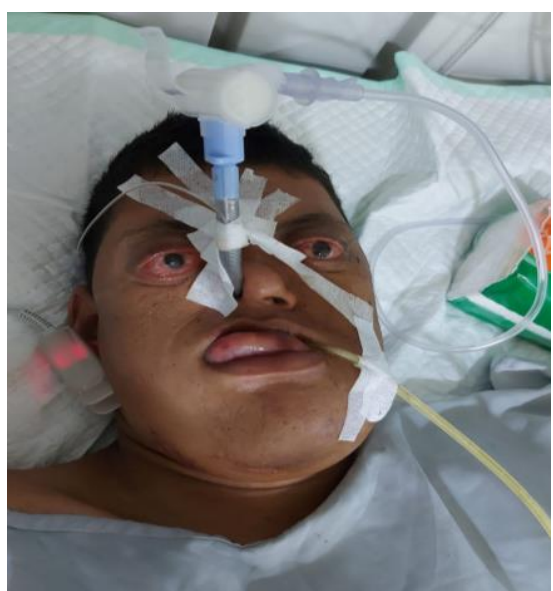

(b)

Figure 1: Anatomical abnormality of exophthalmos in the patient nasal patency, 2-finger mouth opening, Mallampati score difficult to evaluate because of pain, and syndactyly in the extremities (Figure1 \& 2). Other physical examination was normal. Laboratory examinations showed an increase in the leukocyte count $(17,500 / \mu 1)$, a prolonged prothrombin time (PT) $16.8 \mathrm{sec}$, and an increase in the INR value $(1,370)$.

\begin{tabular}{lll}
$\begin{array}{l}\text { Table 1: Vital signs monitoring pre and post- } \\
\text { intubation }\end{array}$ & $\begin{array}{l}\text { Pre- } \\
\text { intubation }\end{array}$ & $\begin{array}{l}\text { Post- } \\
\text { intubation }\end{array}$ \\
\hline Indicator & $\begin{array}{l}115 / 62 \\
(\mathrm{mmHg})\end{array}$ & $\begin{array}{l}127 / 72 \\
(\mathrm{mmHg})\end{array}$ \\
\hline Blood pressure & $76(\mathrm{bpm})$ & $82(\mathrm{bpm})$ \\
Heart rate & $20(\mathrm{bpm})$ & $22(\mathrm{bpm})$ \\
Respiratory rate & $99(\%)$ & $99(\%)$ \\
$\begin{array}{l}\text { Oxygen saturation } \\
\left(\mathrm{SpO}_{2}\right)\end{array}$ & &
\end{tabular}

The patient was sent for various radiological examinations. The posteroanterior (PA) view of chest and the lateral and anteroposterior (AP) views of the neck did not show any abnormalities. Waters position X-ray showed fractures in the left temporoparietal region, nasal septum, and left mandibular body with soft tissue swelling around it. In addition, there were hematosinus at bilateral frontal, bilateral ethmoidal, bilateral maxillary and right sphenoid sinuses. The patient also had a depressed fracture of the left temporoparietal bone and left mandibular body with soft tissue swelling around it as seen on a lateral AP head radiograph (Figure 3).

Next, a non-contrast head Multislice Computerized Tomography (MSCT) was performed and the following results were obtained:

1. Multiple intracerebral hemorrhages (ICH) in left frontotemporoparietal lobe $(7 \mathrm{ml})$

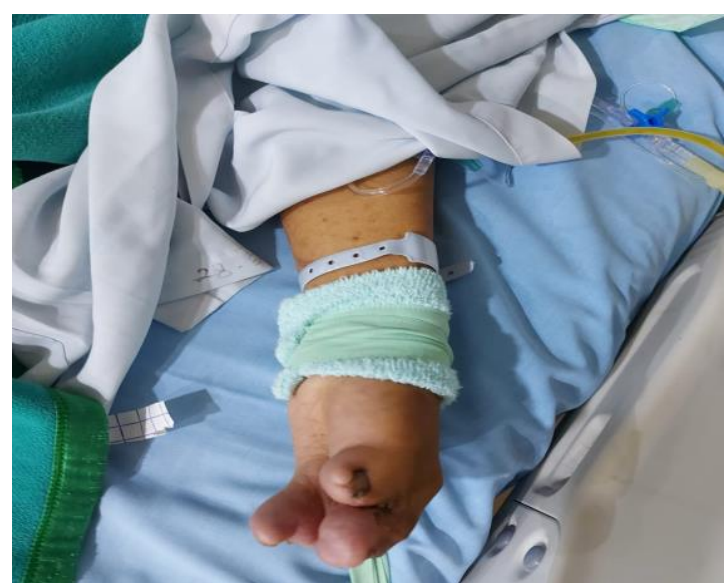

Figure 2: Upper limb syndactyly in the patient

2. Brain edema

3. Pneumocephaly left temporal region

4. Hematosinus in bilateral frontal, bilateral ethmoidal, bilateral maxillary, and right sphenoid sinuses with nasal septal hematoma and left hematomastoid

5. Depressed fracture of the left parietal and squamous pars of the left temporal bone and fracture of the left mandibular body, nasal septum, fractures of the medial wall of the both frontal sinuses, the lateral and medial walls of both ethmoid sinuses of the anterior wall, lateral and medial bilateral maxillary sinuses and lateral wall of right sphenoid sinus and fracture of left zygomatic arch

6. Subgaleal hematoma with subcutaneous emphysema in the left frontotemporoparietal region

The neurosurgeon established a diagnosis of mild brain injury with GCS E4V4M6, decided to suture left 
zygomaticus region and mandibular fracture after planned conservative therapy. The anesthesia department assessed and labeled the patient as ASA III, and planned general anesthesia with awake nasotracheal intubation with fiberoptic bronchoscope.

\section{Anesthesia Management}
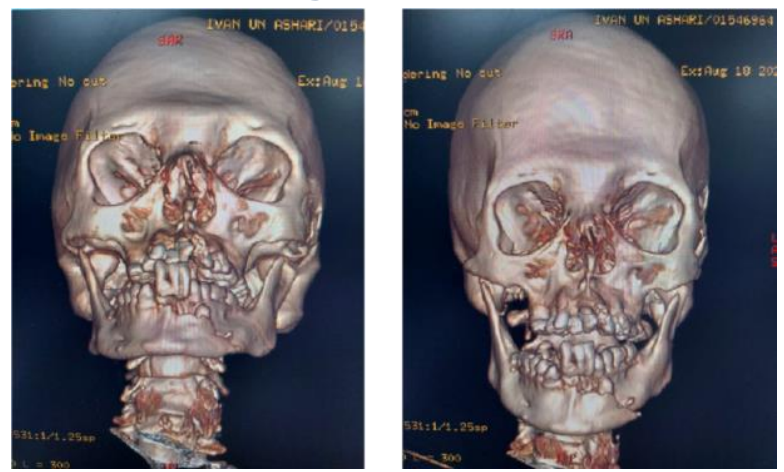

Figure 3: MSCT examination results in patients

The plan of action was maxillofacial reconstruction. Intubation was judged to be difficult with direct laryngoscopy, so it was performed using fiberoptic laryngoscope with full preparations for tracheostomy. Five minutes before intubation, the patient was given fentanyl $50 \mu \mathrm{g}$ and lidocaine $80 \mathrm{mg}$. Lidocaine was also sprayed into the oropharynx. Intubation was performed with a fiberoptic laryngoscope using a non-kinking endotracheal tube No. 7.0.

The patient's head was flexed and the tube was slowly inserted through the well-patented nose over the fiberoptic laryngoscope. After the endotracheal tube entered the trachea, it was connected to the breathing circuit and given propofol $50 \mathrm{mg}$ IV. Maintenance was done with sevoflurane $2 \%$ in air and oxygen.

After the operation was completed, extubation was not performed in the operating room. The patient was shifted to the Intensive Care Unit (ICU) and extubation performed when fully conscious.

\section{Discussion}

Our patient had typical features of AS; e.g., syndactyly on both hands and feet, flat forehead, deeper temporal area, shallow orbit with protruding eyes, and wise distance between the eyeballs. The anesthetic problem in this patient was the expected difficulty in intubation and ventilation (decreased left nasal patency) due to anatomical abnormalities of the airway. This was due to hypoplasia of the middle face. ${ }^{6}$ Patients with AS have profuse secretions which can lead to increased airway irritability, a higher incidence of bronchospasm, and recurrent respiratory infections. Craniofacial anatomic abnormalities are often associated with airway obstruction, especially during sleep and can lead to obstructive sleep apnea. ${ }^{7}$

Obstructive apnea can arise due to decreased airway caliber or total obstruction, which can occur in the form of congenital bony nasal stenosis (CBNS), choanal atresia, nasal septal deviation, narrowed nasopharynx or
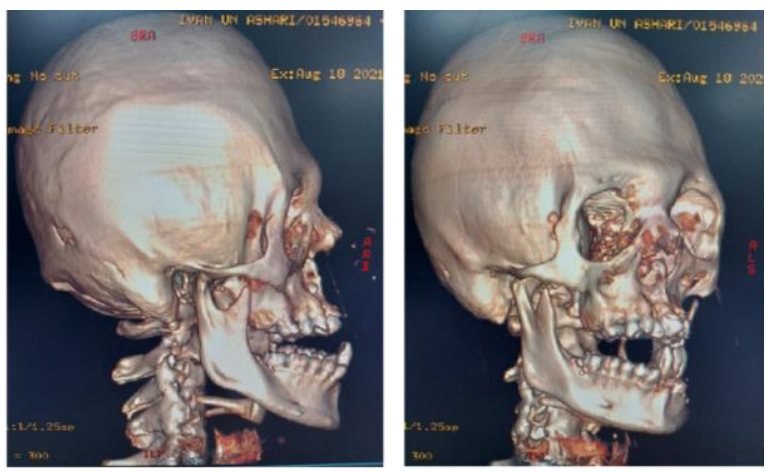

oropharynx, thick long soft palate, lateral palatal edema, and cartilage trachea. ${ }^{8}$ Central apnea in AS can arise from increased intracranial pressure, due to a combination of anatomical abnormalities of the cranium, with cerebrum resulting in ventriculomegaly and tonsillar herniation through the foramen magnum (Chiari malformation). Central apnea results in suppression of the respiratory drive. Increased intracranial pressure can also result in impaired neuromuscular control of airway patency. ${ }^{9}$

As a result of graded airway obstruction and the additional occurrence of central apnea, airway management in AS involves several treatment modalities.

In this patient, the difficult airway was managed by opting awake nasal intubation technique with fiberoptic laryngoscope. The procedure was performed using a 5 $\mathrm{mm}$ scope as a guide to insert the nasal endotracheal under direct visualization of the vocal cords.

Preoperative evaluation and optimization is important in these patients. Essential instruments such as a properly sized airway device, LMA, endotracheal tube, and emergency tracheostomy kit should be readily available. The use of regional anesthetic techniques in addition to general anesthesia can help reduce the need for opioids during the intra and postoperative period. ${ }^{7}$

Other than the difficult airway, another challenge for the anesthesiologist is vascular access. Limb deformities and previous surgical procedures make intravenous access more difficult in AS patients. As a result, some anesthesiologists feel that for short procedures, e.g., dressing changes or radiological examinations using computed tomography (CT), intravenous access is not mandatory. In an emergency, intraosseous or 
intramuscular access can be used. ${ }^{6}$ In this patient, there was no difficulty in securing intravenous access even though there were abnormalities in the patient's limbs.

A discrete history and thorough physical examination will help the anesthesiologist foresee the expected difficulties and allow him to plan and prepare accordingly. As the saying goes, "vigilance is the price of safety".

\section{Conflict of interest}

None declared by the authors.

\section{Authors' contribution}

All authors took part in the management of the case as well as the manuscript preparation.

\section{References}

1. Wenger TL, Hing AV, Evans KN. Apert Syndrome. 2019 May 30. In: Adam MP, Ardinger HH, Pagon RA, Wallace SE, Bean LJH, Gripp KW, et al. (eds). GeneReviews ${ }^{\circledR}$. Seattle (WA): University of Washington, Seattle; 1993-2022.2. Verma S, Draznin M. Apert syndrome. Dermatol Online J. 2005;11(1). [PubMed]
3. Ileri Z, Goyenc YB. Apert syndrome: A case report. Eur J Dent. 2012;6(1):110-113. [PubMed] DOI: 10.1055/s-0039-1698939

4. Bansal T, Jaiswal R, Hooda S, Mangla P. Apert syndrome: Anaesthetic concerns and challenges. Egypt J Anaesth. 2015;31(1):85-87. DOI: 10.1016/j.egja.2014.09.004

5. Azoury SC, Reddy S, Shukla V, Deng CX. Fibroblast growth factor receptor 2 (FGFR2) mutation related syndromic craniosynostosis. Int J Biol Sci. 2017;13(12):1479-1488. [PubMed] DOI: 10.7150/ijbs.22373

6. Barnett S, Moloney C, Bingham R. Perioperative complications in children with Apert syndrome: A review of 509 anesthetics. Paediatr Anaesth. 2011;21(1):72-77. [PubMed] DOI: 10.1111/j.1460-9592.2010.03457.x

7. Patel $K$, Sawant $P$, Chavan $D$. Anesthesia management in a patient of Apert syndrome. Anesth Essays Res. 2013;7(1):133. [PubMed] DOI: 10.4103/0259-1162.114021

8. Xie C, De S, Selby A. Management of the airway in apert syndrome. J Craniofac Surg. 2016;27(1):137-141. [PubMed] DOI: $10.1097 /$ SCS. 000000000002333

9. Zandieh SO, Padwa BL, Katz ES. Adenotonsillectomy for obstructive sleep apnea in children with syndromic craniosynostosis. Plast Reconstr Surg. 2013;131(4):847-852. [PubMed] DOI: 10.1097/PRS.0b013e3182818f3a

10. Butterworth JF, Mackey DC, Wasnick JD. Morgan \& Mikhail's Clinical Anesthesiology. Vol 7. 5th ed. Mc Graw Hill; 2013. 